\title{
Thermal Management of Batteries in Advanced Vehicles Using Phase-Change Materials
}

\author{
Gi-Heon Kim*, Jeffrey Gonder*, Jason Lustbader*, and \\ Ahmad Pesaran**
}

Hybrid electric vehicles (HEVs) and plug-in hybrid electric vehicles (PHEVs) are promising technologies to help reduce the amount of petroleum consumed for transportation. In both HEVs and PHEVs, the battery pack is a key component to enabling their fuel savings potential. The battery is also one of the most expensive components in the vehicle. One of the most significant factors impacting both the performance and life of a battery is temperature. In particular, operating a battery at elevated temperatures reduces its life. It is therefore important to design and implement effective battery thermal management systems. This paper analyzes the suitability of phase-change material (PCM) for battery thermal management in HEV and PHEV systems. A prototype PCM/ graphite matrix module (that was not fully optimized for HEV applications) was evaluated experimentally under geometric and vehicle-simulation-based drive cycles. The results were used to validate a thermal model. The model was then used to explore the benefits and limitations of PCM thermal management. This study suggests that PCM can provide a peak-temperature-limiting benefit in vehicle applications, but the overall battery thermal management solution must rely on active cooling or on limiting the battery's power output (or both) to avoid high temperatures during continuous cycling. Ultimately, vehicle designers will need to weigh the potential increase in mass and cost associated with adding PCM to the thermal management system against the anticipated benefits: a smaller active cooling system, less need to limit battery power output in high-temperature conditions, and/or potentially reduced exposure to momentary or localized high cell temperatures.

Keywords: Battery Thermal Management, Phase-Change Material, Hybrid Electric Vehicle, PHEV

\section{INTRODUCTION}

Driven by persistent concerns about the global environment and petroleum supplies and prices, interest in advanced and alternative vehicle powertrain technologies continues to grow. Hybrid electric vehicles (HEVs) are an effective technology for reducing the overall amount of petroleum consumed for transportation. An HEV uses an electrical energy storage system, usually composed of batteries, to operate more efficiently. Achieving greater per-vehicle petroleum displacement, however, will require the use of more advanced propulsion technologies. Plug-in hybrid electric vehicles (PHEVs) are one such advanced technology. PHEVs have promise to achieve near-term market penetration and thus significant petroleum displacement [1].

\footnotetext{
* Research Engineers

National Renewable Energy Laboratory

1617 Cole Blvd, Mail Stop 1633, Golden, CO 80401

Fax: 303-275-4415

** Principal Engineer

National Renewable Energy Laboratory

1617 Cole Blvd, Mail Stop 1633, Golden, CO 80401

Fax: 303-275-4415
}

In both HEVs and PHEVs, the battery pack is a key component of their fuel savings potential, and the battery is also one of the most expensive components in the vehicle [2]. Because the battery's performance unavoidably declines over the life of the vehicle, the battery must be carefully managed to minimize degradation and the impact that such degradation can have on vehicle performance and fuel consumption. One of the most significant factors impacting battery performance and life is temperature. In particular, operating the battery at high temperatures can lead to damaging electrochemical side reactions. For some batteries, higher temperatures will also increase the internal rates of thermal reactions, which lead to even greater heat generation, higher temperatures, and a "thermal runaway" condition potentially ending in fire or explosion [3].

To avoid the adverse impacts of high-temperature conditions, battery systems designed for vehicle applications typically employ convective thermal management in the form of air or liquid cooling [4]. Thermal management system designs can vary widely in complexity and in cost. On the low end of complexity, the management system might use a small fan to circulate ambient 
air from the environment through the battery chamber. This approach is fairly simple and inexpensive to implement, but it might not manage heat effectively enough to permit high-rate battery use in all conditions or to prevent a sizable temperature imbalance in the pack. At the high end of complexity, the management system might include a temperature-controlled liquid cooling circuit passing across the cells in the pack. This approach would regulate the pack temperature evenly and allow full power capability over a range of ambient temperatures and operating conditions. In practice, present-day battery thermal management solutions fall between these two extremes and employ trade-offs among management effectiveness, complexity, and cost. Developing more effective, simpler, and less expensive thermal management approaches would assist in the further development of affordable battery packs and increased market penetration of HEVs and PHEVs.

One alternative battery thermal management approach that has been investigated for soldier-carried battery applications is passive thermal management using phase-change material (PCM) [5]. In order to maximize the amount of stored battery energy available for its primary function, a passive management solution is appealing. This can be accomplished by integrating a structure with the battery so that the PCM is in direct thermal contact with the battery cells. When a soldier draws power from the battery, usually during a constant current discharge, the added thermal mass of the PCM system helps to absorb the waste heat given off by the cells and slows their temperature rise. If the temperature continues to rise, especially when the battery operates at a high rate and in high ambient temperatures, the PCM melts and effectively limits peak temperature. In addition, the thermally conductive structure holding the PCM provides a fast heat transfer path through a battery module, minimizing the temperature difference between the cells in the module.

This paper explores whether thermal management using PCM could provide similar benefits in HEV or PHEV applications. Vehicle batteries can have duty cycles that are significantly different from those of soldier applications. Therefore, PCM technology should be carefully assessed to determine whether it would improve upon existing vehicle battery thermal management technologies.

\section{APPROACH}

Experimental and analytical tools were used to evaluate the use of PCM for thermal management of HEV and PHEV energy storage systems. The electrical and thermal performance of a battery was characterized experimentally using both geometric and simulated

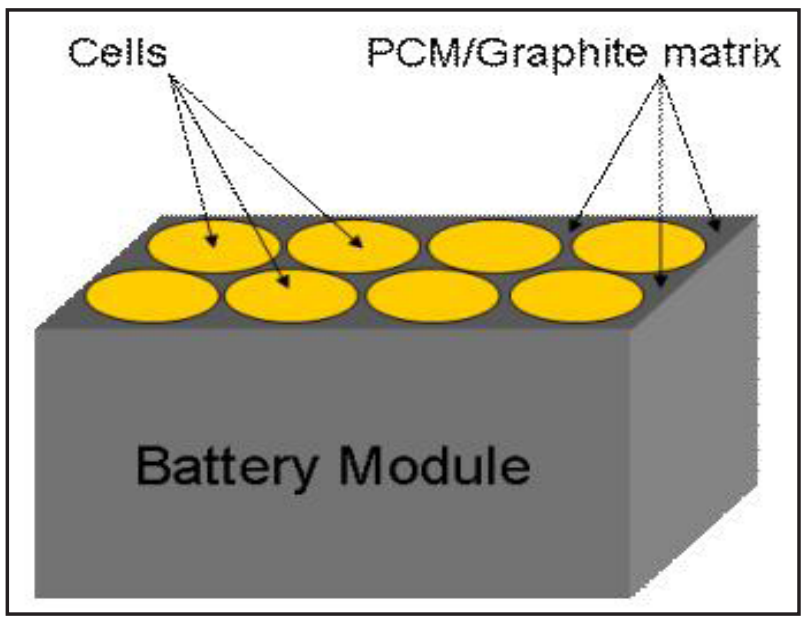

Figure 1: Conceptual schematic of a battery module with $\mathrm{PCM}$ /graphite thermal management

in-vehicle duty cycles. These results were then used to validate a model of the battery thermal management system. This model was used to compare various thermal management approaches, to determine suitable conditions for use of PCMs, and to explore different design scenarios.

A prototype $\mathrm{PCM}$ /graphite matrix module was provided by AllCell Technologies LLC (AllCell ${ }^{\circledR}$ ) for concept evaluation. The module design, shown in Figure 1 , has a porous graphite matrix, impregnated with wax, that provides structure and heat dissipation [5][6]. The graphite matrix holds the wax like a sponge would. The high-conductivity graphite also provides a low-resistance heat path for effective heat transfer to the wax. The wax absorbs thermal energy through both the sensible heat and the latent heat of phase change. The battery cells are inserted into the PCM/graphite matrix structure as shown. It should be noted that the module's intended design was for PHEV and LEV applications and was not optimized for HEV applications [7].

\subsection{Experimental Methods}

The prototype PCM module provided by AllCell was tested in the Battery Thermal Management Laboratory at the National Renewable Energy Laboratory (NREL). The module uses twenty $18650 \mathrm{Li}$-ion cells, with five parallel by four series cell strings. This results in a 7.5 Ah nominal capacity rating and a $12-16.8 \mathrm{~V}$ operating range. The module weighs $1.246 \mathrm{~kg}$ with nominal dimensions of $10 \mathrm{~cm}$ by $8.5 \mathrm{~cm}$ by $6.5 \mathrm{~cm}$. The module was placed in an environmental chamber and attached to a wooden testing jig, as shown in Figure 2. The jig al- 


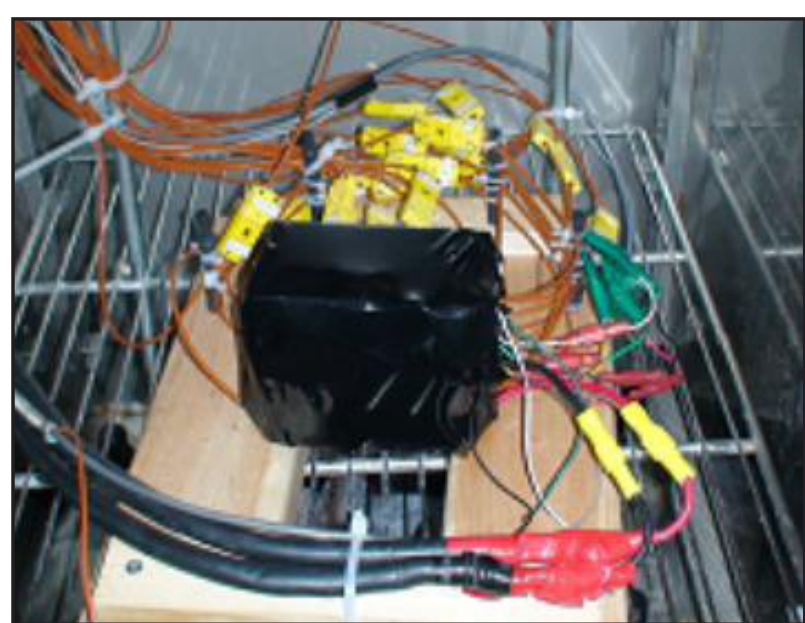

Figure 2: Instrumented AllCell PCM module on testing jig in the environmental chamber

lowed air flow around the module and prevented thermal contact with highly conductive external surfaces. Voltage measurements were taken for each of the four series-connected strings; the system accuracy was better than $\pm 0.41 \%$ of the reading. Temperature measurements were taken using shielded K-type thermocouples calibrated at the system level using a liquid calibration bath, giving an uncertainty of $\pm 0.35^{\circ} \mathrm{C}$.

Figure 3 shows the locations of the thermocouple measurements. Quarter symmetry assumptions were made in determining the positions. Ungrounded insertion probes were used to measure half-depth points. An Aerovironment ABC-150 battery cycler was used to load the module electrically. A data acquisition system collected voltage, temperature, and current data.

\subsection{Thermal Modeling Approach}

In addition to the preliminary experimental evaluation, a lumped capacitance model was developed to evaluate the performance of PCM battery thermal management. It was validated for the prototype technology using the experimental data. The model was then used to predict expanded applications under various conditions and operating scenarios. The lumped approach is useful in system-level analysis, evaluating variations over time of the battery's thermal response. This model assumes that heat transfer inside a module is much faster than the heat exchange rate between the system and the ambient environment. When this assumption is true, the Biot number is much less than 1 , and a lumped temperature can effectively represent the overall system temperature. The thermally lumped analysis approach is reasonable for the prototype module, since the examined module's Biot number is ap-

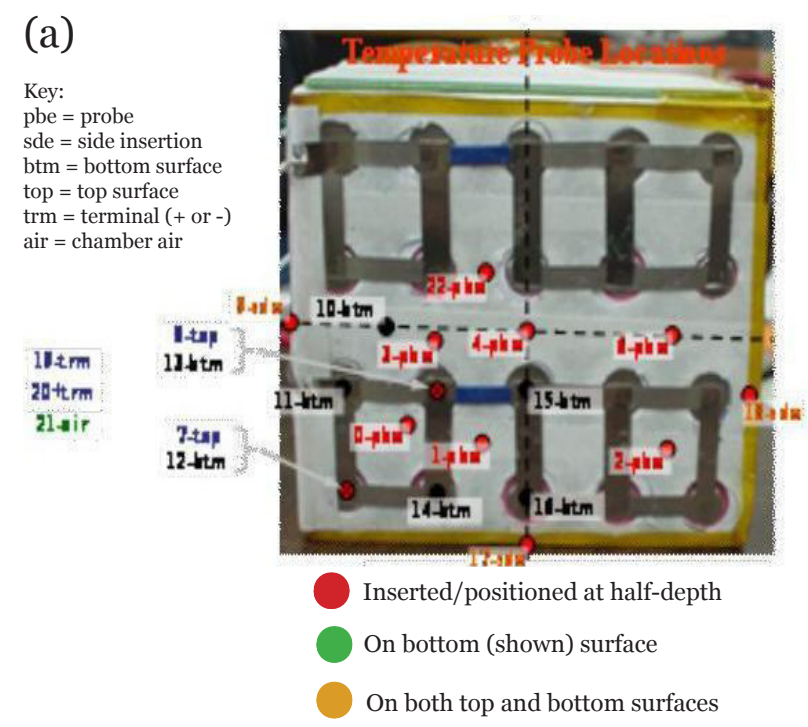

(b)

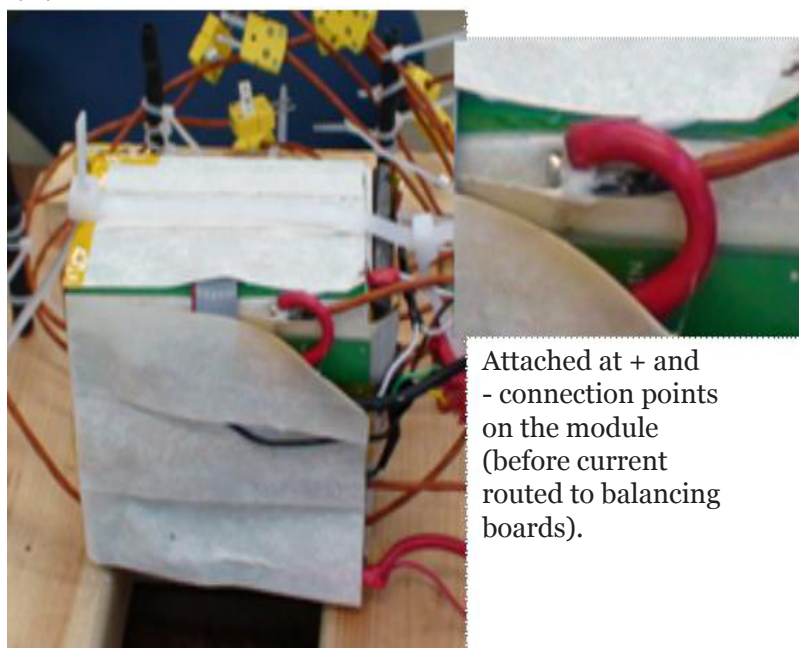

Figure 3: Instrumentation pictures of (a) thermocouple locations and names and (b) detail showing terminal temperature measurement

proximately 0.005 . The energy conservation equation for the lumped system is as follows:

$$
M_{s y s}\left(c_{p, s y s}+D \lambda_{s y s}\right) \frac{d T}{d t}=h A_{s u r f}\left(T_{a m b}-T\right)+Q_{g e n}
$$

where the Gauss pulse used for D is

$$
D=e^{-\left(T-T_{m e l t}\right)^{2 / \delta T}} / \sqrt{\prod \delta T^{2}}
$$


(a)

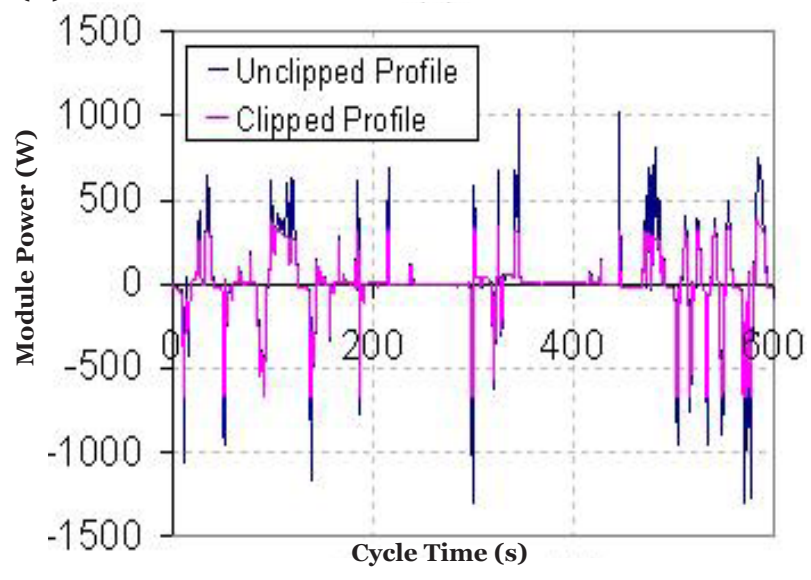

(b)

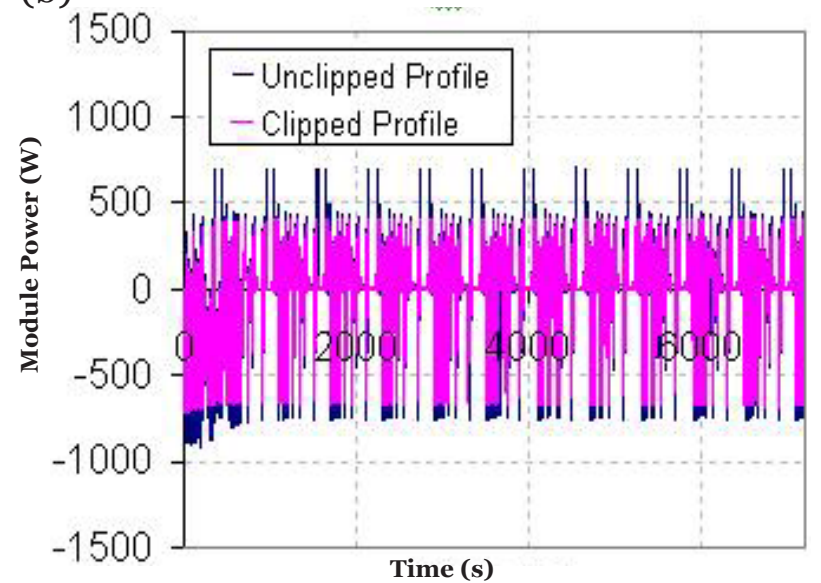

Figure 4: Clipped and unclipped battery power profiles for (a) HEV operation on a single USo6 cycle and (b) PHEV operation over many repeated USo6 cycles (positive values indicate battery charging)

(a)

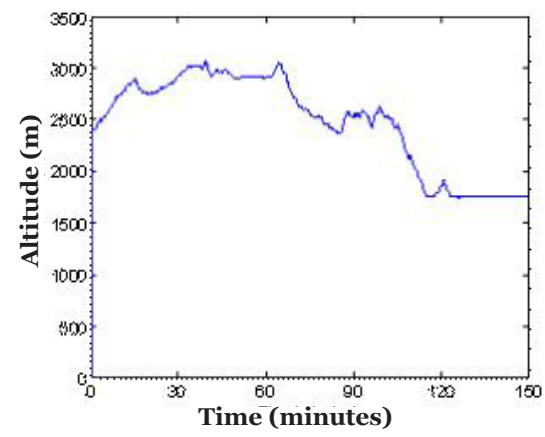

(b)

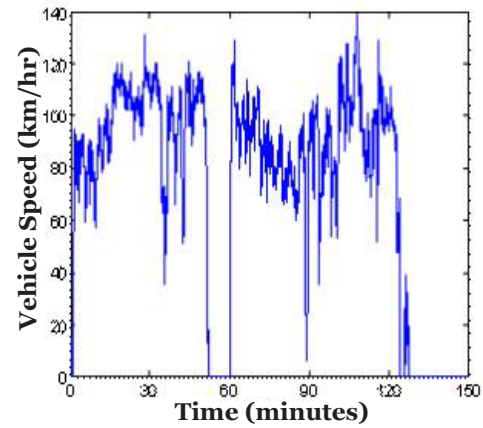

(c)

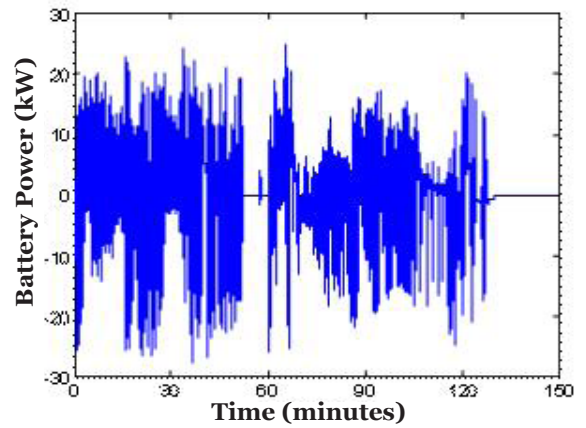

Figure 5: Prius mountain driving profile for Brown Canyon showing (a) altitude, (b) speed, and (c) battery power

\subsection{Test Profile Development}

The experimental and modeling approaches require the selection of an electrical test profile over which to evaluate a module's thermal performance during invehicle use. The profiles for testing the prototype module were developed using a vehicle simulation program with models constructed for a previously published comparative analysis of HEVs and PHEVs [8]. Vehicle simulations were conducted over repetitions of an aggressive driving profile, known as the US06 cycle, to determine the power demand for the vehicle's battery pack.

The prototype module's cells were not intended for vehicle use; therefore, an HEV pack designed to use these modules was oversized with respect to energy content but slightly under-powered. The low power capability of the prototype module caused it to miss the requested
HEV power profile, resulting in peak "clipping." The model was validated for the clipped cycle and then used to investigate the full unclipped HEV cycle. Figure 4(a) shows the clipped and unclipped HEV power profiles. For PHEV use, the power-to-energy ratio of the prototype module makes it most suitable for a PHEV10. For PHEV cycle testing, conservative module voltage and current limits again clipped the peak power during the cycle. Modeling evaluation used both the clipped and unclipped profiles shown in Figure 4(b). Note that the most intensive battery use for the PHEV cycle occurs during charge-depleting (CD) operation.

To support PCM modeling evaluation with batteries that are more suitable for HEV applications, additional battery power profiles were obtained by testing a 2006 model year Toyota Prius. To obtain the power profiles, battery voltage and current measurements were recorded from the vehicle controller area network, or CAN, 
bus during on-road mountainous driving in Colorado. The pack-level power profile was then scaled down to evaluate PCM thermal management for different prospective HEV battery cells. Figure 5 shows the collected profile information for mountainous driving on a route through Colorado's Brown Canyon.

\section{RESULTS}

\subsection{Analysis of Intermittent High-Rate Discharge Application}

The duty cycle for soldier-carried battery applications, for which PCM/graphite thermal management has been investigated, can be characterized by intermittent high-rate discharges. For a large-battery HEV/ PHEV, this type of loading represents a worst-case continuous power draw, such as providing propulsion

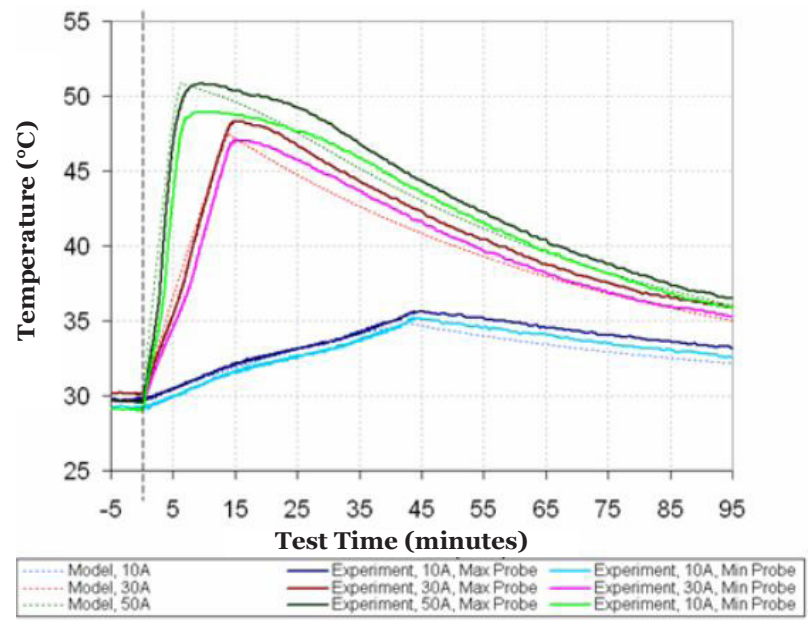

Figure 6: Experiment and model comparison for a single discharge

(a)

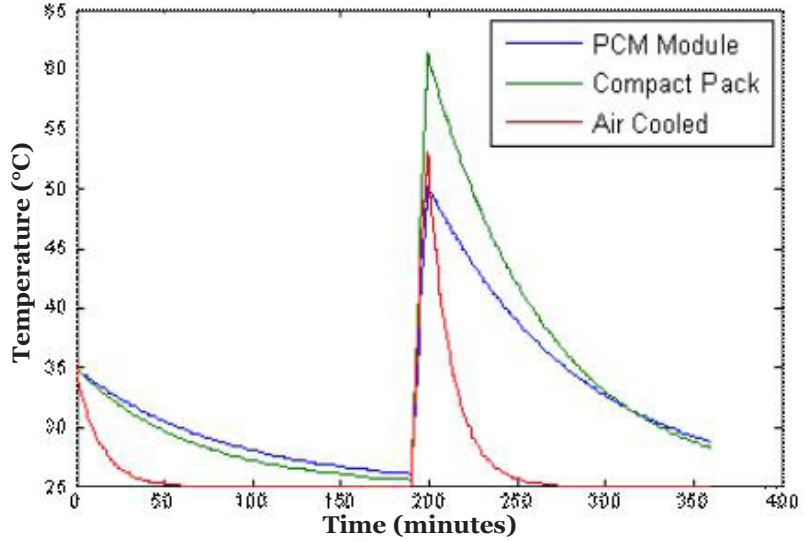

or assistance on a long hill climb. For a small-battery $\mathrm{HEV}$, this could represent providing full accessory pow ${ }^{-}$ er from the battery with the engine off during a long stop.

Figure 6 shows the lumped capacitance model compared with experimental data for $10 \mathrm{~A}, 30 \mathrm{~A}$, and 50 A single-discharge cases at an average ambient temperature of $29.6^{\circ} \mathrm{C}$. The model is evaluated against the minimum and maximum mid-plane temperatures as measured by the insertion probes (pbe- $0-4,5$, and 22 in Figure 3), because they best characterize the internal bulk temperature represented by the model. To capture heat generation over the full range of discharge, the model uses an equivalent series resistance (ESR) of $0.05 \Omega$ per cell for discharge (or $0.04 \Omega$ per module) as measured with the NREL calorimeter.

After validation testing, the model was used to compare the performance of PCM thermal management with forced air-cooling $\left(\mathrm{h}=15 \mathrm{~W} / \mathrm{m}^{2} \mathrm{~K}\right)$, and natural convection cooling $\left(\mathrm{h}=6 \mathrm{~W} / \mathrm{m}^{2} \mathrm{~K}\right)$. The "Compact Pack" in Figure 7 has the worst thermal performance of the configurations considered because of its closely packed cells and complete reliance on natural convection for cooling. The figure shows the model results for a cooldown from an initial elevated temperature, followed by a single 40 A discharge for 9 minutes and a subsequent cool-down.

For the $25^{\circ} \mathrm{C}$ ambient condition shown in Figure 7(a), forced-air cooling limits the peak module temperature and allows it to cool quickly after the discharge is complete. The larger thermal mass of the PCM material results in a slightly lower peak temperature than that of air cooling, despite a slower heat rejection rate. The larger thermal mass and smaller heat transfer at the surface also cause a slower cool-down rate for the PCM

(b)

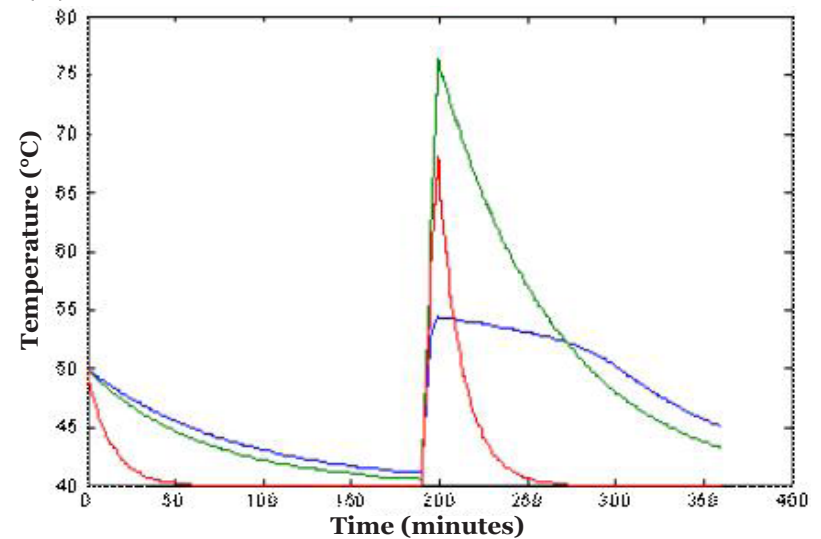

Figure 7: Lumped capacitance model for a 9-min, 40-A discharge at (a) $\mathrm{T}_{\text {ambient }}=25^{\circ} \mathrm{C}$ and (b) $\mathrm{T}_{\text {ambient }}=40^{\circ} \mathrm{C}$ 
(a)

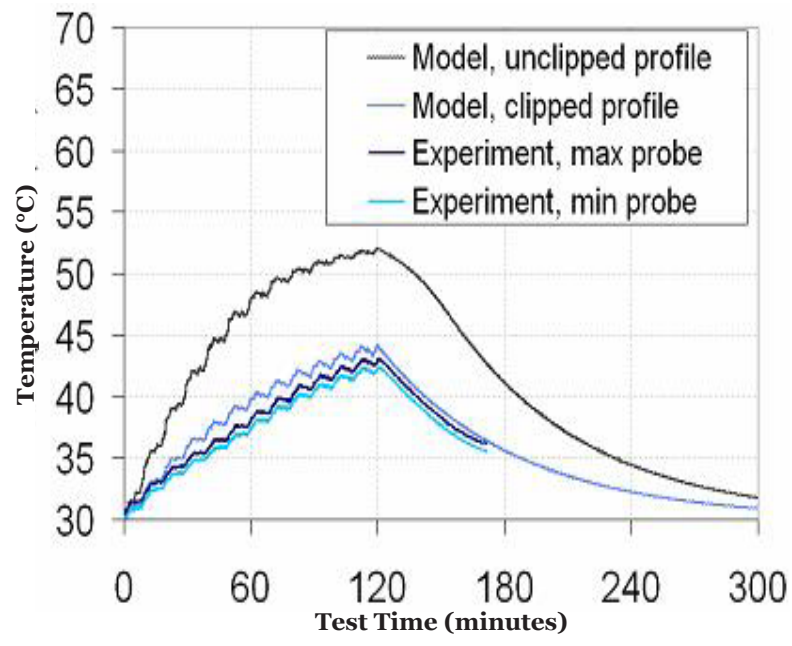

(b)

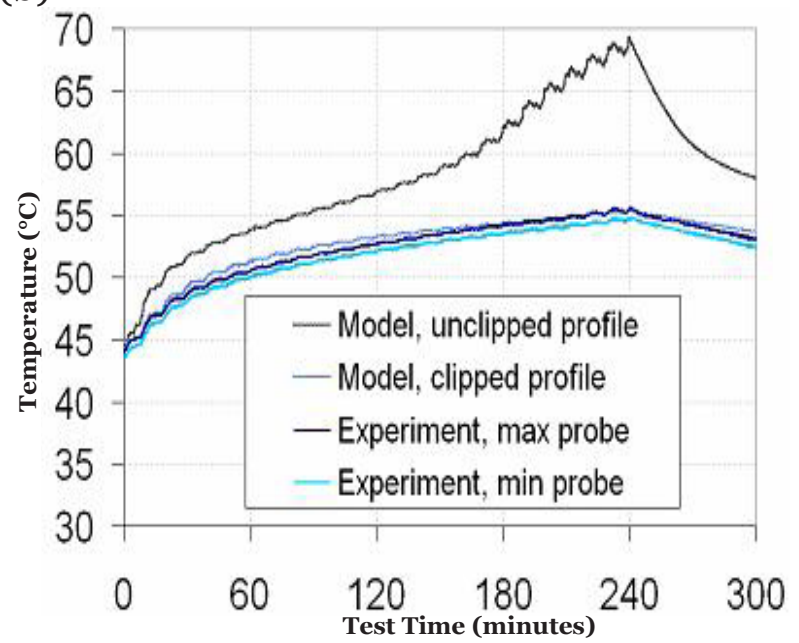

Figure 8: Prototype module temperature rise during aggressive HEV cycling (modeling and clipped profile experimental results): (a) 12 ten-minute cycles in $30^{\circ} \mathrm{C}$ ambient and (b) 24 ten-minute cycles in $45^{\circ} \mathrm{C}$ ambient

module. In the $40^{\circ} \mathrm{C}$ ambient case shown in Figure 7(b), the PCM module reaches the lower bound phasechange temperature and prevents a further rise in temperature by storing latent heat as the wax within the matrix melts. This results in a much lower peak temperature and a slower cool-down as the stored heat is slowly rejected to the environment.

\subsection{Analysis of Aggressive HEV Cycling Application}

While an intermittent discharge analogous to the duty cycle from soldier-carried battery applications could occur occasionally in a vehicle, the battery thermal management system must also handle the continuous battery charge/discharge cycling more typical of long-duration vehicle operation. Therefore, the prototype module's thermal performance was also evaluated over repetitions of the aggressive HEV power profile derived from the vehicle simulations. Figure 8 shows the resulting temperature profile from both modeling and experimentation at ambient temperatures of $30^{\circ} \mathrm{C}$ (Figure $8(\mathrm{a})$ ) and $45^{\circ} \mathrm{C}$ (Figure $8(\mathrm{~b})$ ). The lower group of curves in each figure shows modeling validation using the clipped power profile run during experimentation.

The model is in good agreement with the experiment for the $30^{\circ} \mathrm{C}$ ambient case and is in excellent agreement for the $45^{\circ} \mathrm{C}$ case. Repeated cycling with an irregular power profile creates the wavy appearance of the temperature rise shown in Figure 8(a). This behavior also appears during the initially steep temperature rise shown in Figure 8(b), but is dampened during the flatter temperature rise in the PCM melting region be- tween $51^{\circ}$ and $55^{\circ} \mathrm{C}$. Referring to the average between the minimum and maximum probe temperatures, the model predicts the peak temperature to within $1.4^{\circ} \mathrm{C}$ for the $30^{\circ} \mathrm{C}$ ambient case and to within $0.2^{\circ} \mathrm{C}$ for the $45^{\circ} \mathrm{C}$ case.

The validated model was then used to simulate continuous high-rate cycling cases. The unclipped US06 module power profile and aggressive geometric profile (Figure 9) were repeatedly cycled to quantify the heat generation from the prototype module. The geometric profile used is the most thermally aggressive cycle for the given module; therefore, it can be considered an upper bound for continuous cycling. The US06 and geometric cycles resulted in $9.2 \mathrm{~W} /$ module and $45 \mathrm{~W} / \mathrm{mod}^{-}$ ule, respectively.

The performance of three different thermal management methods for the module (PCM Only, Air-Cooled PCM, and Air-Cooled Only) were compared for continuous HEV cycles, as shown in Figure 10. The model assumed that heat exchange occurs at the module's surface in both the PCM cases and at the cell surfaces in the Air-Cooled Only case. The heat transfer coefficient for forced convection was set at $15 \mathrm{~W} / \mathrm{m}^{2} \mathrm{~K}$ and at 5 $\mathrm{W} / \mathrm{m}^{2} \mathrm{~K}$ for natural convection in the PCM Only case. Ambient and cooling air temperatures were $30^{\circ} \mathrm{C}$ in all cases.

For US06 cycling, both the Air-Cooled PCM and the Air-Cooled Only cases reached their periodic steadystate temperatures of around $40^{\circ} \mathrm{C}$ in 1 hour. The AirCooled Only case has a lower steady-state temperature than the Air-Cooled PCM case because it has a larger 
(a)

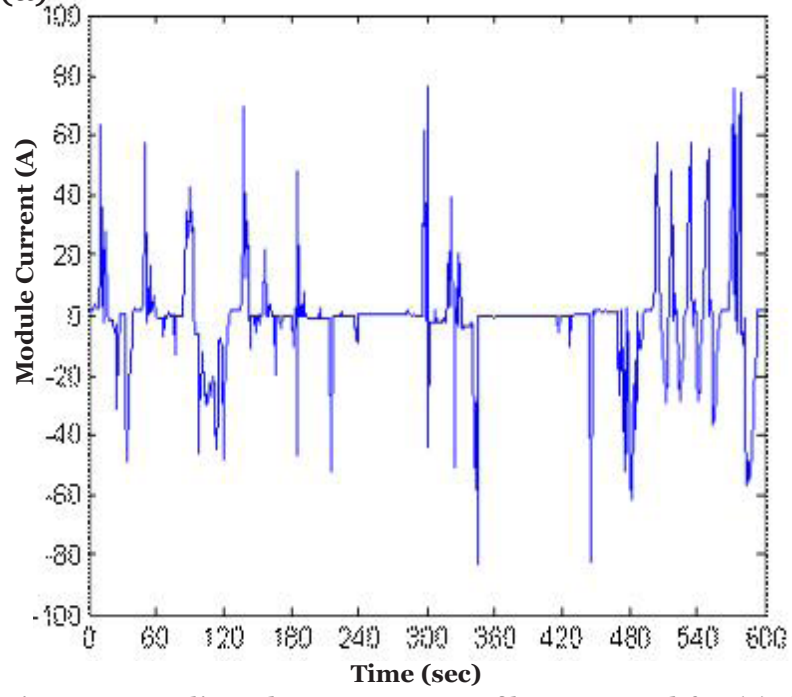

(b)

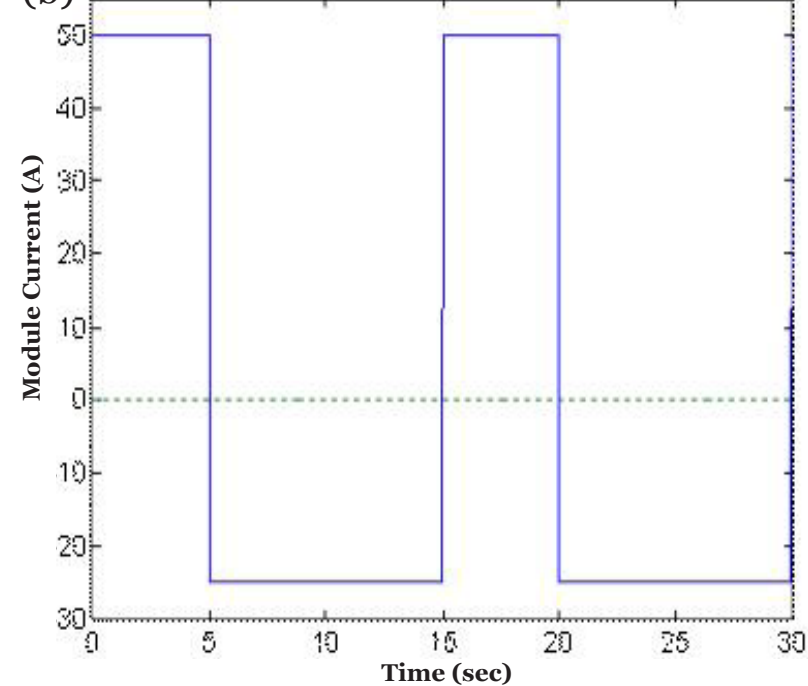

Figure 9: Unclipped USo6 HEV profile generated for (a) the prototype module and (b) an aggressive geometric profile

(a)

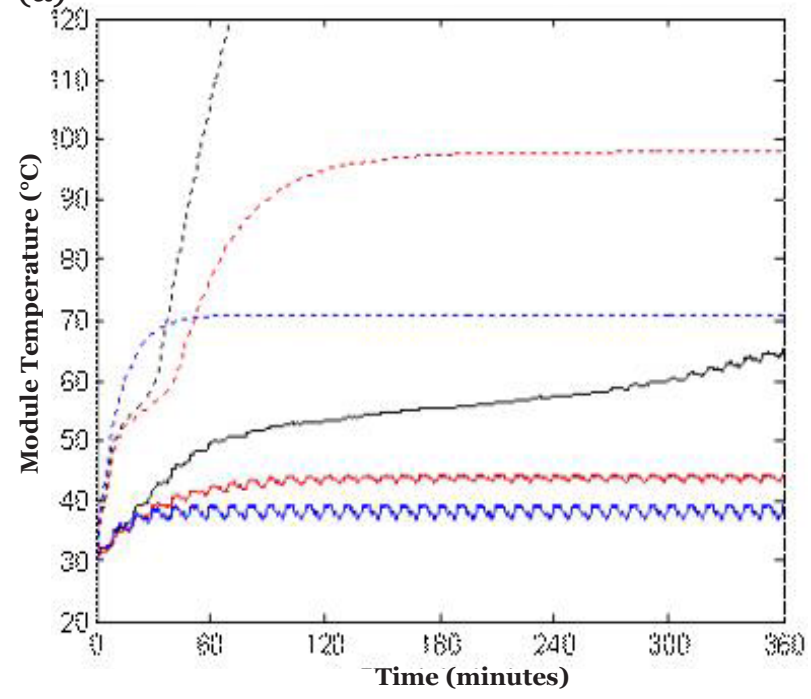

(b)

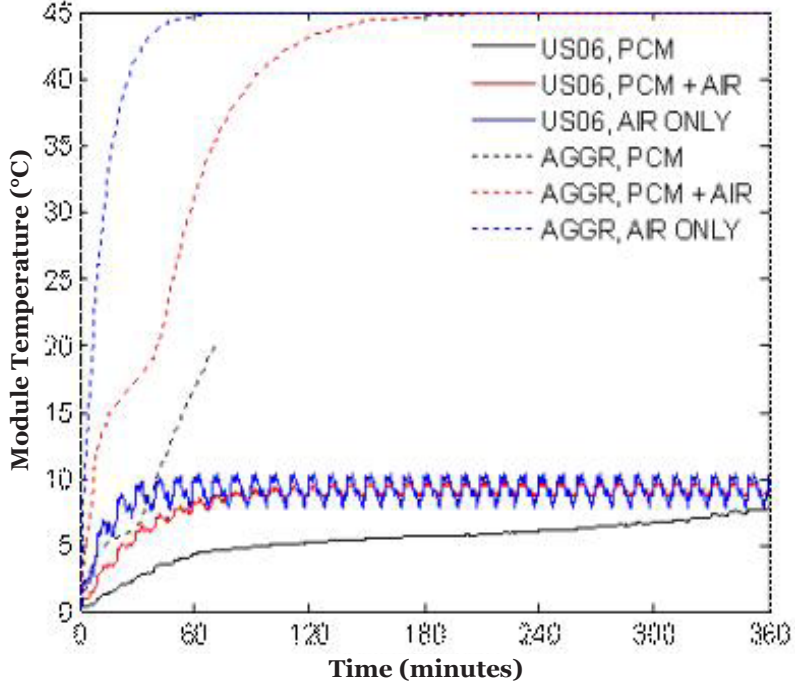

Figure 10: Comparison of the performance of different thermal management methods under high-rate continuous cycling: (a) temperatures profile and (b) heat rejection rate comparison

heat transfer area provided by the surface of all the cells. On the other hand, the heat rejection from PCM without air cooling is not as efficient as in the forced convective cooling cases. Even though the temperature increase is delayed by the latent heat from PCM melting, heat simply accumulates in the system until it reaches a higher steady-state temperature (greater than $65^{\circ} \mathrm{C}$ ) than that of the air-cooled modules.

Under aggressive geometric cycling, resulting in very high-rate heat generation (dotted lines in Figure 10), all three thermal management approaches stayed in a similar temperature range for the first 30 minutes of cycling. After this initial heat-up, continued cycling caused the temperatures of the modules to diverge. With very high-rate heat generation, system thermal mass is more important in determining the initial temperature rise than heat exchange at the system's surface. Therefore, the initial rise in the PCM regulated module temperatures was effectively limited by the PCM's latent heat. If cycling is terminated before 40 minutes, the PCM would effectively prevent the module from being exposed to battery-damaging high temperatures. However, since the steady-state temperature at continuous 
cycling is determined by the heat rejection rate at the module's surface, sufficient heat rejection from the system is required to keep the module temperature within a reasonable range for long-term cycling. Temperature increases in the PCM module without additional cooling may not be acceptable for high-rate continuous cycling.

Since the prototype module was not designed for HEV applications, virtual battery modules were created to be numerically simulated in the real-world driving scenarios described and shown in Figure 5. In order to use the Prius driving data, a compatible lithium-ion technology was assumed for the virtual battery pack to replace the stock nickel-metal hydride (NiMH) module, assuming that the virtual module provided identical electrical responses to the vehicle system. Table 1 lists the battery characteristics of the stock module and the virtual module. The required thermal parameters were derived from the values listed and used for the simulations.

The virtual module contains twelve D26H65 (26-mm diameter and 65-mm height) virtual cells, 6 in parallel and 2 in series. The cells were assumed to be imbedded in the PCM/graphite matrix with $3 \mathrm{~mm}$ of spacing in 4-by-3 alignments. One virtual module would replace one stock module. The efficiency of the virtual module was assumed to be $94 \%$. This constant efficiency value was used to evaluate the heat generation from the module without assuming the details of the thermal characteristics of the virtual cells. The surface of all the cells was used for cooling in the Air-Cooled Only case; only the external surface of the PCM matrix was available for heat exchange in the PCM cases. The battery initial temperature and air temperature were assumed to be $30^{\circ} \mathrm{C}$, which implied that cabin air would be used for battery cooling. The heat transfer coefficient at the cooling surface was $10 \mathrm{~W} / \mathrm{m}^{2} \mathrm{~K}$ when the fan was on and 4 $\mathrm{W} / \mathrm{m}^{2} \mathrm{~K}$ when the fan was off. The forced-air convection mode was activated if the pack temperature exceeded $45^{\circ} \mathrm{C}$ while the vehicle was in operation.

Figure 11 compares battery temperature variations and heat rejection rates from the modules for different
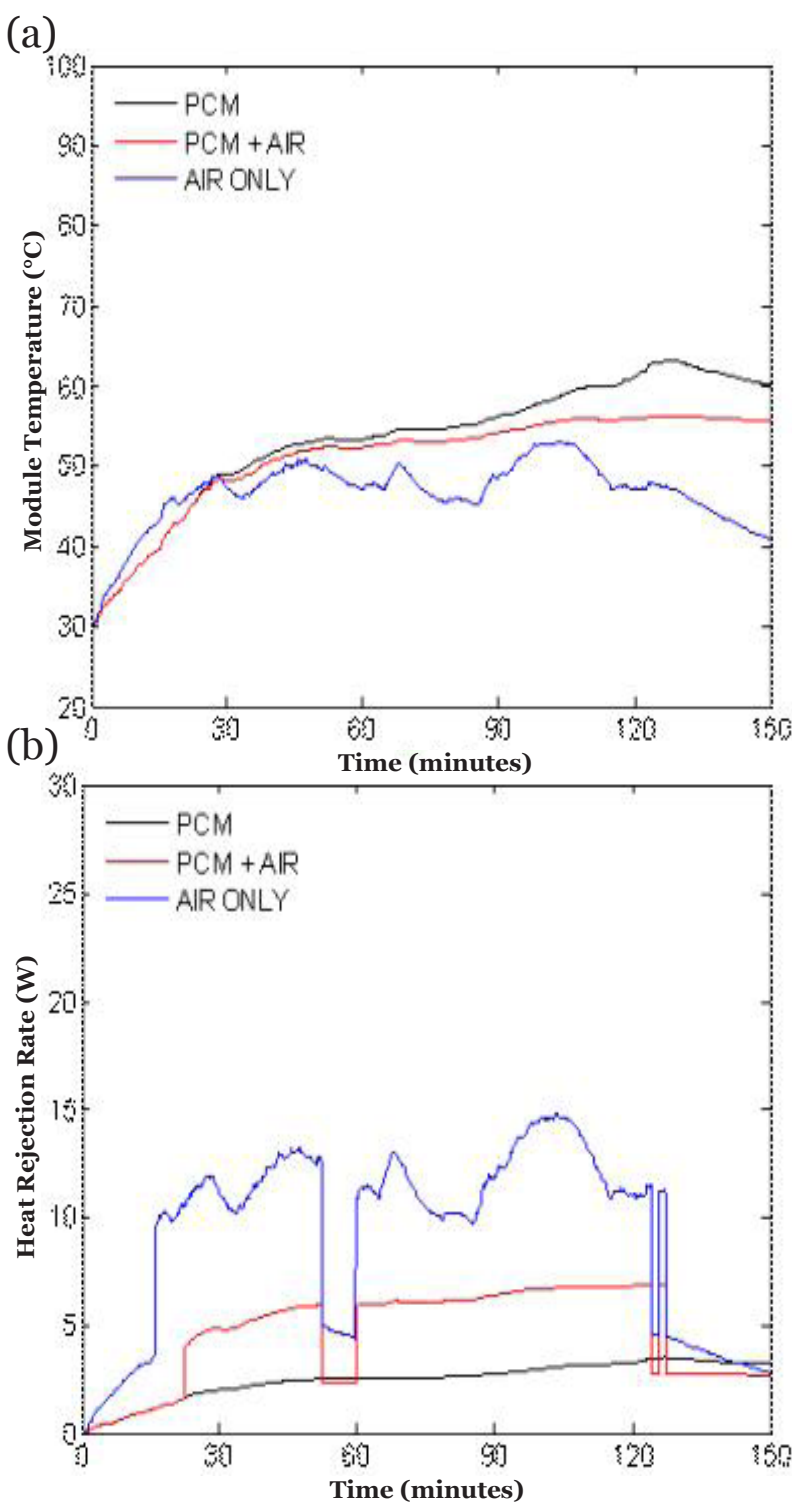

Figure 11: Comparisons of (a) battery temperature variations and (b) heat rejection rates from the modules for different thermal management methods using the Brown Canyon driving cycle $\left(\mathrm{h}_{\text {fan,on }}=10 \mathrm{~W} / \mathrm{m}^{2} \mathrm{~K}\right.$ and $\mathrm{h}_{\text {fan,off }}=4$ $\left.\mathrm{W} / \mathrm{m}^{2} \mathrm{~K}\right)$

\begin{tabular}{|c|c|c|}
\hline & $\begin{array}{l}\text { Prius Stock } \\
\text { NivH Module }\end{array}$ & $\begin{array}{l}\text { Virtual } \\
\text { Li-Ion }\end{array}$ \\
\hline PIE & 28 & 27 \\
\hline Specific Power Cunkgy & 1300 & 1820 \\
\hline Specific Energy GNh/kg) & 46 & 67 \\
\hline Mass Density $\left(\mathrm{Kg}^{\prime} / \mathrm{m}^{3}\right)$ & -2500 & -2000 \\
\hline Specific Heat $(\mathrm{J} / \mathrm{kg} . \mathrm{K})$ & -850 & -850 \\
\hline
\end{tabular}

Table 1: Battery characteristics of the stock module and the virtual module 
thermal management methods during the "Brown Canyon" real-world driving cycle. The average heat generation rate was about $9.9 \mathrm{~W} /$ module for 150 minutes of operation. The initial temperature rise was higher for the Air-Cooled Only case because of its smaller thermal mass. With the fan on, however, the heat removal rate for the Air-Cooled Only case became high enough, compared with the heat generation rate, to keep the module temperature in the desirable range during the drive. The PCM Only and the Air-Cooled PCM cases show similar temperature profiles for given conditions. However, due to the lack of efficient heat removal from the system and consequent heat accumulation, the temperature in the PCM Only case exceeded $60^{\circ} \mathrm{C}$ after 120 minutes. Incorporating a PCM matrix tends to reduce the available cooling surfaces in small-cell modules. This reduction in cooling area makes the heat rejection for the Air-Cooled PCM less efficient than it is in the Air-Cooled Only case, as shown in Figure 11(b).

Large-format cells are known to have difficulties with thermal management. One of the reasons for this is the reduced surface area per volume. Increasing the cell size will reduce the available heat-exchange area for a given total volume of cells. Battery temperature variations in a large-cell module at the same conditions were simulated and are shown in Figure 12(a). The large-cell virtual module features four series-connected D41H145 (41-mm diameter and $145-\mathrm{mm}$ height) virtual cells. The cells were assumed to be imbedded in the PCM/ graphite matrix with $5 \mathrm{~mm}$ of spacing in 2-by-2 alignments. One virtual module would replace two stock NiMH modules.

For the Air-Cooled Only case, the large-cell module temperature increased significantly higher than the small-cell module temperature. In contrast, the large-

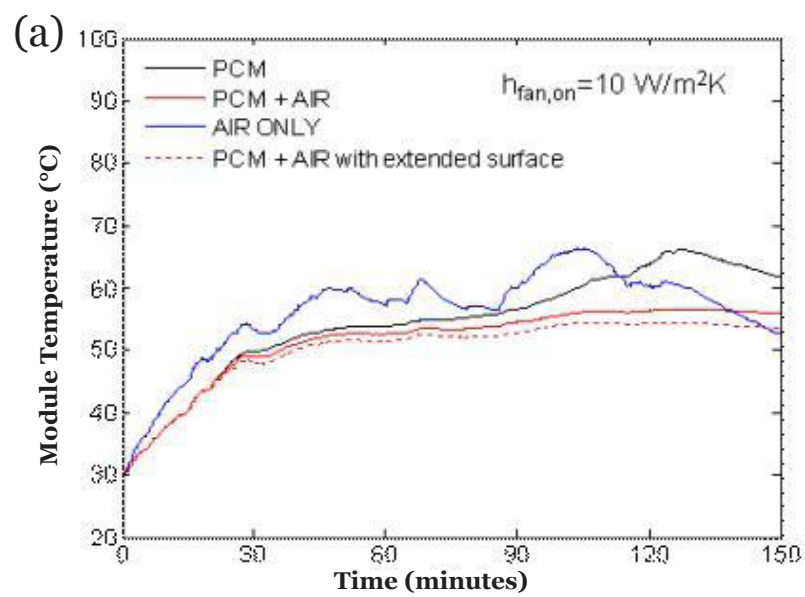

cell module temperature for the Air-Cooled PCM case was maintained at less than $55^{\circ} \mathrm{C}$. The effect of the reduction in cooling surface area due to size was not as significant in the PCM case as in the air-cooled case. In addition, using large cells makes it easier to extend the cooling surface in a PCM module, for example, by drilling air channels through the PCM/graphite matrix. The dotted line in the graph shows the temperature of the Air-Cooled PCM case with an extended surface that matches the heat exchange area of the Air-Cooled Only case. As shown in Figure 12(b), the Air-Cooled PCM case does not demonstrate as clear a benefit over the Air-Cooled Only case if the heat transfer coefficient of the system increases to $15 \mathrm{~W} / \mathrm{m}^{2} \mathrm{~K}$.

As battery technology advances, battery power density will increase. A more advanced battery would have fewer cells than earlier battery designs while providing an equivalent amount of power to the vehicle system. This higher power battery would likely cause higher volumetric heat generation. This impact was briefly investigated by doubling the power rate of the large-cell virtual module and increasing its efficiency from $94 \%$ to $96 \%$. The results are shown in Figure 13. The higher cell heating rate combined with the poor heat rejection rate of the PCM Only case leads to very high temperatures (up to nearly $90^{\circ} \mathrm{C}$ ). An Air-Cooled PCM module can maintain the temperature near $55^{\circ} \mathrm{C}$. To keep the peak module temperature of the Air-Cooled Only case below $55^{\circ} \mathrm{C}$, the heat transfer coefficient must be larger than $20 \mathrm{~W} / \mathrm{m}^{2} \mathrm{~K}$, as shown in Figure 13(b).

\subsection{Analysis of PHEV1o Cycling Application}

Figure 14 shows both experimental and modeling results for the PHEV10 battery cycle at $30^{\circ} \mathrm{C}$ (Figure $14(\mathrm{a}))$ and $45^{\circ} \mathrm{C}$ (Figure $\left.14(\mathrm{~b})\right)$ ambient temperatures.

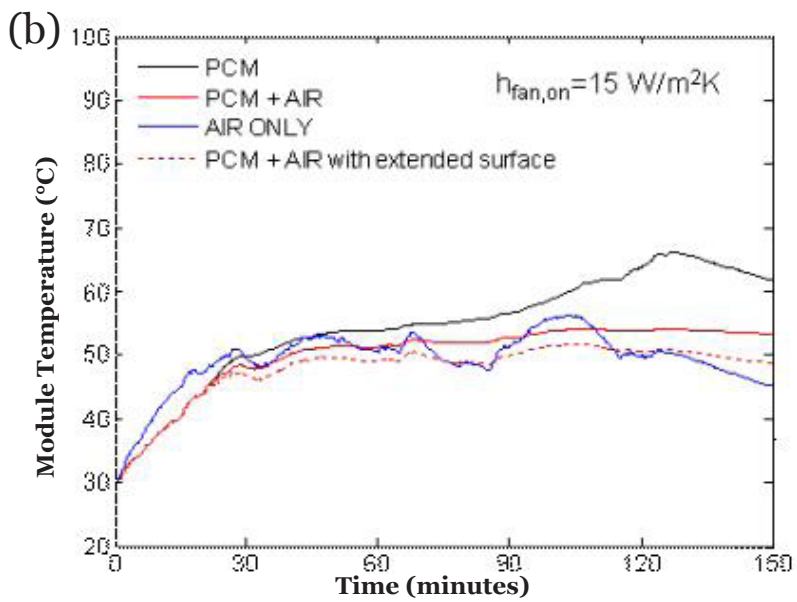

Figure 12: Comparison of battery temperature variations in a large-format cell module with a forced convection heat transfer coefficient of (a) $h_{\text {fan,on }}=10 \mathrm{~W} / \mathrm{m}^{2} \mathrm{~K}$ and (b) $\mathrm{h}_{\text {fan,on }}=15 \mathrm{~W} / \mathrm{m}^{2} \mathrm{~K}$ for different thermal management methods during the Brown Canyon driving cycle 
(a)

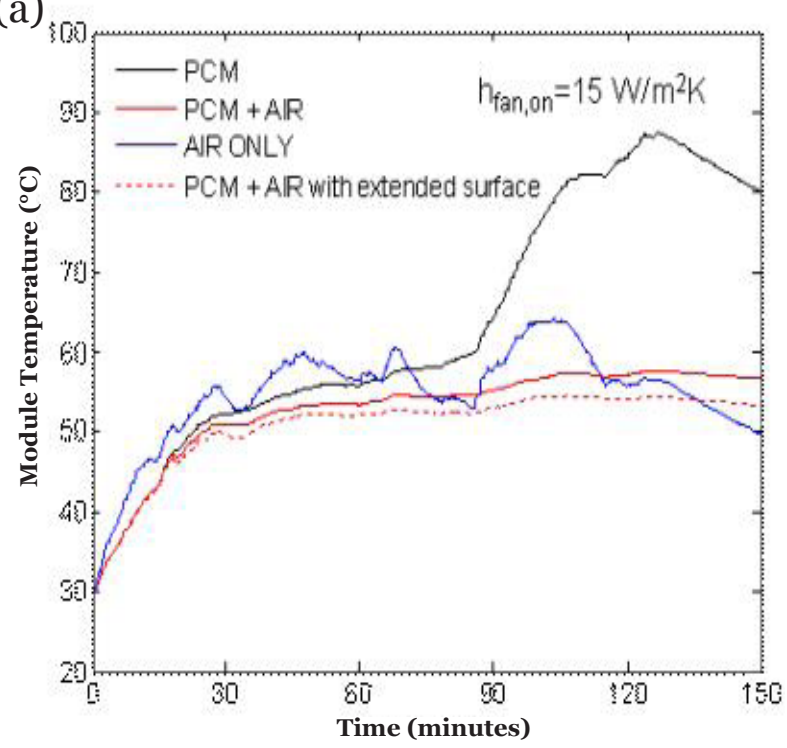

(b)

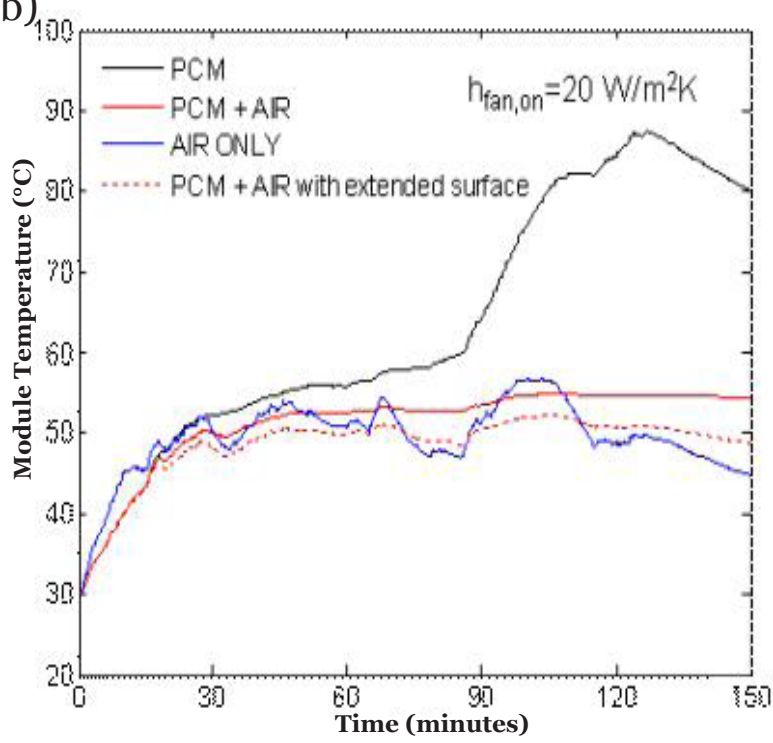

Figure 13: Comparison of battery temperature variations in a large-power-cell module with a forced convection heat transfer coefficient of (a) $\mathrm{h}_{\text {fan,on }}=15 \mathrm{~W} / \mathrm{m}^{2} \mathrm{~K}$ and (b) $\mathrm{h}_{\text {fan,on }}=20 \mathrm{~W} / \mathrm{m}^{2} \mathrm{~K}$ for different thermal management methods during the Brown Canyon driving cycle

(a)

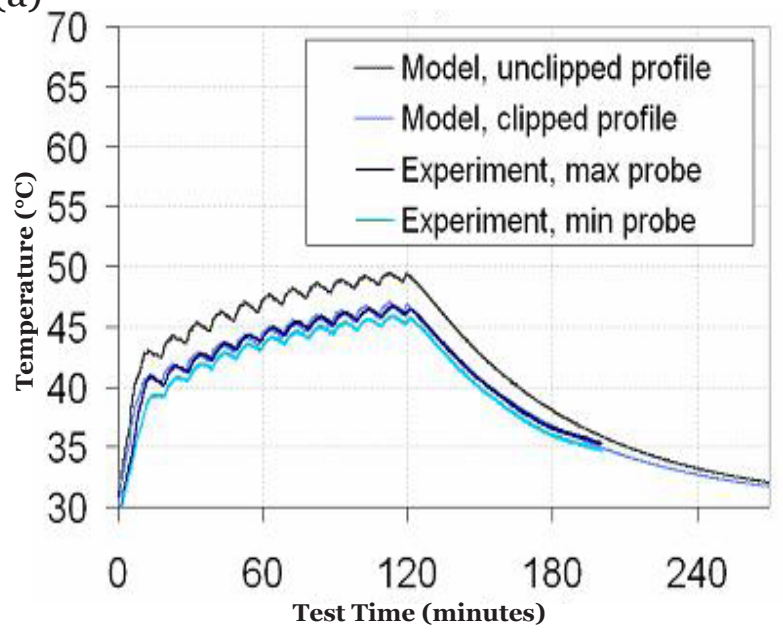

(b)

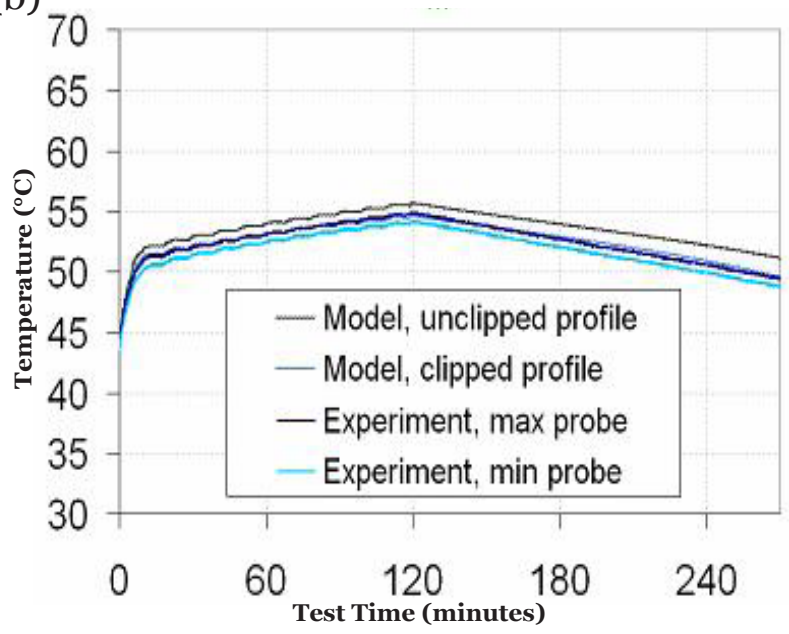

Figure 14: Prototype module temperature rise during PHEV1o battery operation over 12 consecutive USo6 cycles (modeling and clipped profile experimental results): (a) in $30^{\circ} \mathrm{C}$ ambient conditions and (b) in $45^{\circ} \mathrm{C}$

ambient conditions

Good agreement is again observed between the experimental and modeling results for the clipped profile. Because the prototype module is a better fit for PHEV10 applications, much less clipping occurred from the original cycle. This resulted in very similar temperature profiles for both the clipped and unclipped cases.

In Figure 14(a), a very rapid temperature rise occurs initially during intensive CD battery use, followed by a much more gradual rise during subsequent, less intensive charge-sustaining (CS) operation (heat generation is $28 \mathrm{~W} /$ module in the CD period and $6.6 \mathrm{~W} /$ module in the CS period). The total temperature rise stays below the PCM melting region for this 2-hour cycling case, whereas Figure 14(b) shows that a high starting temperature causes rapid heating during the CD operation to bring the module temperature into the phase-change region. During phase change, the temperature rise 
slows sufficiently to remain below $55^{\circ} \mathrm{C}$ through the end of this 2-hour cycle.

Figure 15 compares the prototype module temperature responses for different thermal management methods, assuming module operation in high ambient temperatures using the PHEV10 cycle. The initial temperature and air temperature for cooling were set at $45^{\circ} \mathrm{C}$ and the heat transfer coefficient set at $10 \mathrm{~W} / \mathrm{m}^{2}$ K. As shown in Figure 15(a), the initial CD mode led to a peak temperature greater than $60^{\circ} \mathrm{C}$ for the AirCooled Only case. For the PHEV battery use pattern, high heat generation during the CD portion followed by lower heat generation during the CS portion creates a thermal profile somewhere between intermittent discharge and constant HEV cycling. Even though air cooling is still an efficient way to reject heat from the module (as seen in Figure 15(b)), PCM worked better in limiting the temperature peak that originated in the brief period of high-rate heat generation.

(a)

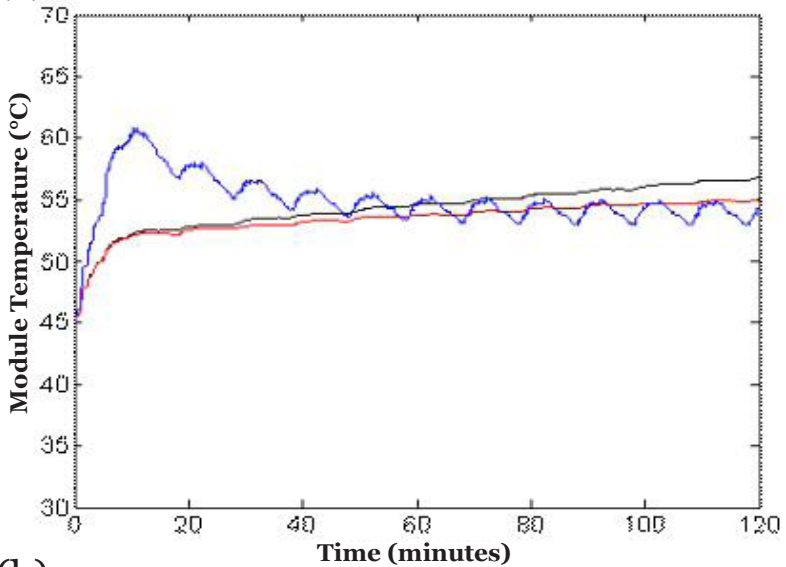

(b)

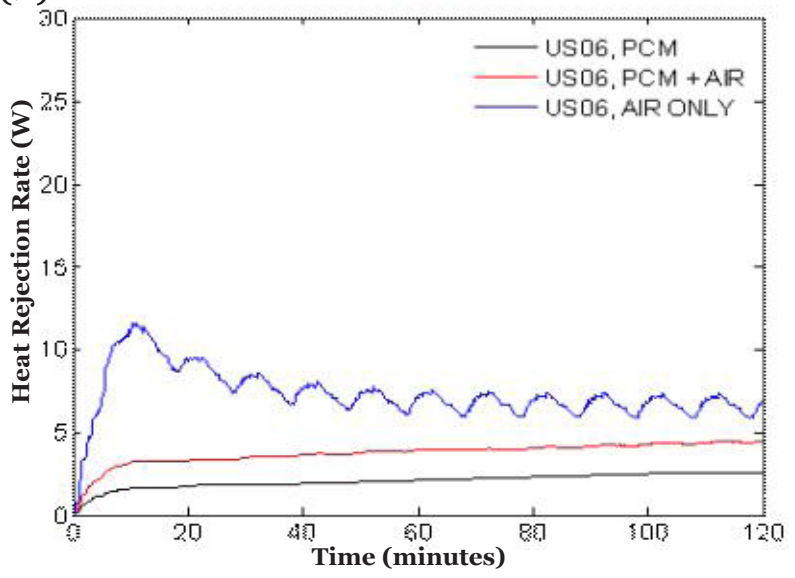

Figure 15: Comparison of prototype module (a) temperature responses and (b) heat rejection rates for different thermal management methods
If the regulated cabin air $\left(30^{\circ} \mathrm{C}\right)$ is used for battery cooling with a slightly higher heat transfer coefficient $\left(15 \mathrm{~W} / \mathrm{m}^{2} \mathrm{~K}\right)$, the peak module temperature of the AirCooled Only case can be limited to a level comparable with that of the PCM Only case (see Figure 16(a)). If the low-temperature cabin air is not available for use in cooling the module, a much higher heat transfer coefficient of $40 \mathrm{~W} / \mathrm{m}^{2} \mathrm{~K}$ would be required to limit the initial peak temperature, as shown in Figure 16(b). In an aircooled system operating in the laminar flow regime, a heat transfer coefficient of $40 \mathrm{~W} / \mathrm{m}^{2} \mathrm{~K}$ can be achieved with small air channels and a channel height of about 2 $\mathrm{mm}$. Because friction pressure loss is more sensitive to air channel height, the air channel design for achieving $40 \mathrm{~W} / \mathrm{m}^{2} \mathrm{~K}$ would be over-designed for PHEV applications in which low-rate volumetric heating is dominant in the CS mode. If PCM is combined with air cooling, infrequent high-temperature $\mathrm{CD}$ operation can be managed with a much more moderate heat transfer co- $^{-}$ efficient of $20 \mathrm{~W} / \mathrm{m}^{2} \mathrm{~K}$, as shown in Figure 16(b). Other

(a)

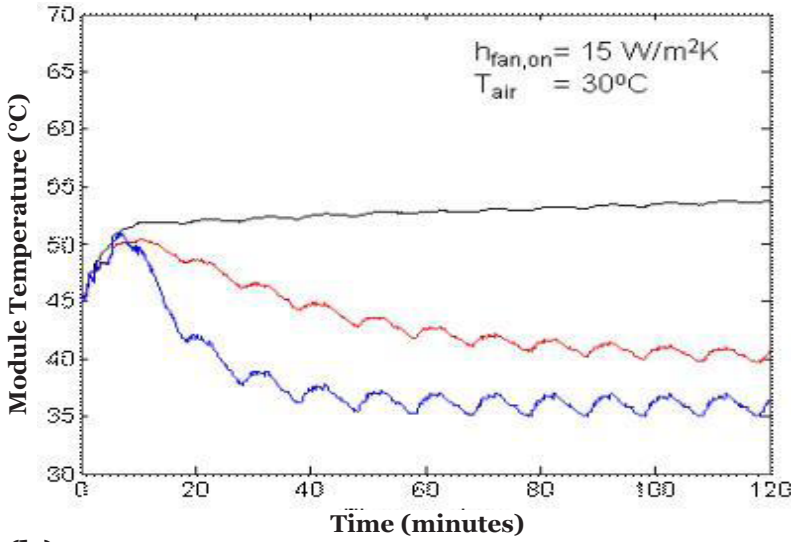

(b)

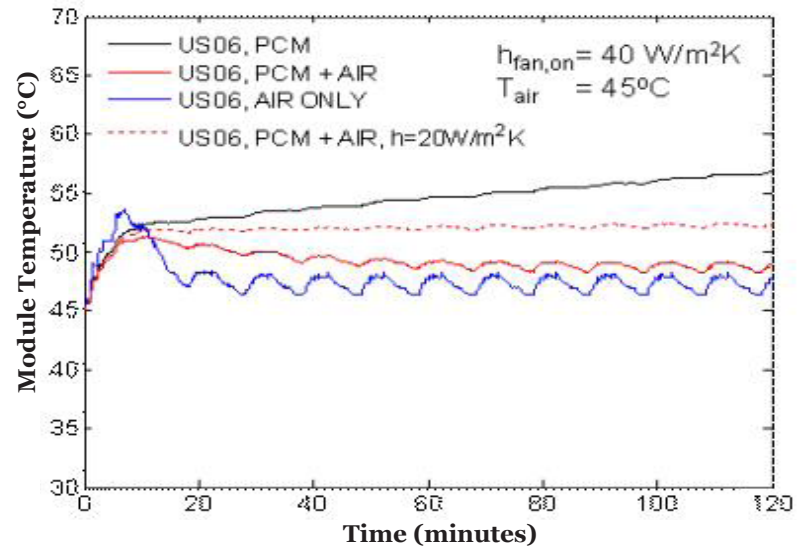

Figure 16: Comparison of prototype module temperature responses for different thermal management methods that limit peak temperatures (a) by using regulated cabin air and (b) by applying a high heat transfer coefficient 
approaches to protect the battery under such extreme conditions include employing a liquid cooling system or restricting battery operation.

\section{SUMMARY AND CONCLUSIONS}

In order to evaluate the potential benefit of battery thermal management using phase-change material in vehicle applications, the prototype module described in this paper was tested and a computational model was developed to predict its thermal performance. The experimental results sufficiently validated the model for use in examining the prototype configuration over a wide range of conditions, as well as for investigating the possible benefits of integrating phase-change material (PCM) thermal management with other vehicle battery implementations.

Using modeling to compare PCM battery thermal management with other solutions indicates that PCM provides the greatest peak-temperature-limiting benefit during short periods of intensive battery use characterized by high heat generation. Phase change limits the peak temperature rise effectively, especially in high ambient temperature conditions. This benefit, however, requires sufficient cooling time after intensive use for adequate heat rejection to the environment. However, when a high average heat generation rate is combined with the poor heat rejection rate, the system will simply continue to accumulate heat and allow its temperature to reach unacceptably high levels. Combining some degree of forced air cooling with the PCM implementation would help speed heat removal from the battery system and would be required to handle the steady heat generation during long periods of continuous charge-sustaining HEV (hybrid electric vehicle) or PHEV (plug-in HEV) battery cycling.

An analysis over continuous cycling conditions suggests that the potential role of PCM in vehicle battery thermal management is not to replace the active cooling system but rather to allow the active cooling system to be downsized or used less frequently. The PCM's excellent capability to prevent temperature excursions during an intensive heat generation event allows the active cooling system to be designed for steady-state rather than transient loads. Combining PCM into an air-cooled system would be most beneficial in a battery system with large-format, high-power cells. Achieving performance comparable to that of the Air-Cooled PCM with forced-air cooling alone may require some or all of the following: (1) chilling the cooling air, (2) incorporating a high heat transfer coefficient system design, or (3) restricting battery use at high temperatures, which is a common current practice [9].
For a PHEV, PCM could provide a buffer against the short period of high heat generation during initial charge-depleting operation, while air cooling should be able to handle the cooling load during less intensive charge-sustaining operation. For PHEVs, PCM may be best suited for low-range applications such as the PHEV10 investigated in this paper, as the lower P/E ratio batteries used in longer range $\mathrm{PHEVs}$ may possess enough thermal mass by themselves to provide a buffer against intermittent temperature spikes.

Areas requiring additional analysis include examining the advantages and disadvantages of PCM in cold ambient temperatures, such as the advantage of delaying battery cool-down during brief stops or the disadvantage of delaying battery warm-up after a long cold-soak. Safety tests need to be conducted to minimize any risks associated with the electrical conductivity of the carbon matrix and the potential flammability of the wax PCM used in this study. In a separate study [10], we concluded that fast heat dissipation through the thermally conductive matrix would reduce the chances of cell-tocell thermal runaway propagation in a module, which serves as a safety benefit of the PCM technology.

The analysis to date suggests that PCM can provide some peak-temperature-limiting benefit in vehicle applications, but that the overall battery thermal management solution must still rely on convective cooling and/or limiting battery power output in order to avoid high-temperature excursions during continuous cycling. Optimizing the PCM design specifically for the peak-temperature-limiting function in a combined AirCooled PCM thermal management system could involve reducing the amount of phase-change material that would otherwise be used and/or lowering the designed melting temperature to further restrict high-temperature exposure. Ultimately, vehicle designers will need to weigh the potential increase in mass and cost associated with adding PCM to the thermal management system against the anticipated benefits of doing so: a smaller active cooling system, less need to limit battery power output in high-temperature conditions, and/ or potentially reduced exposure to momentary or localized high cell temperatures.

\section{ACKNOWLEDGEMENTS}

The U.S. Department of Energy (DOE) Office of Energy Efficiency and Renewable Energy funded this work. We appreciate the support provided by Dave Howell and Tien Duong, DOE Program Managers, FreedomCAR and Vehicle Technologies Program. Special thanks to the research staff of the Illinois Institute of Technology, including professor Said Al-Hallaj for providing 
technical comments and to AllCell Technologies LLC of Chicago, Illinois, for generously donating prototype materials.

\section{REFERENCES}

[1] T. Markel, M. O'Keefe, A. Simpson, J. Gonder, and A. Brooker. Plug-in HEVs: A Near-term Option to Reduce Petroleum Consumption. Milestone Report, $\mathrm{Na}^{-}$ tional Renewable Energy Laboratory, Golden, Colorado 80401, USA, 2005.

[2] T. Markel and A. Simpson. "Cost-Benefit Analysis of Plug-In Hybrid Electric Vehicle Technology." World Electric Vehicle Association (WEVA) Journal, Vol. 1, 2007.

[3] G.-H. Kim, A. Pesaran, and R. Spotniz. "A ThreeDimensional Thermal Abuse Model for Lithium-Ion Cells." Journal of Power Sources, Vol. 170, pp. 476-489, 2007.

[4] G.-H. Kim and A. Pesaran. "Battery Thermal Management Design Modeling." World Electric Vehicle Association (WEVA) Journal, Vol. 1, pp. 126-133, 2007.

[5] S. Al-Hallaj, et.al, "Novel PCM Thermal Management Makes Li-ion Batteries a Viable Option for High Power and High Temperature Applications", The 22nd International Battery Seminar \& Exhibit, Fort Lauderdale, Fl, March 14-17, 2005.

[6] S. Al-Hallaj, et al. U.S. Patent No. US2006/0073377 A1, April 6, 2006.

[7] S. Al-Hallaj, et.al, "Passive Thermal Management Using Phase Change Material (PCM) for EV and HEV Li-Ion Batteries," Proceedings of the Vehicle Power Conference, Chicago, Illinois, September 2005.

[8] J. Gonder, T. Markel, M. Thornton, and A. Simpson. "Using GPS Travel Data to Assess the Real-World Driving Energy Use of Plug-In Hybrid Electric Vehicles (PHEVs)." Accepted for publication in the Transportation Research Record (TRR), Journal of the Transportation Research Board (TRB), 2007.

[9] R. Carlson, et al. "On-Road Evaluation of Advanced Hybrid Electric Vehicles over a Wide Range of Ambient Temperatures." The 23rd International Battery, Hybrid and Fuel Cell Electric Vehicle Symposium and Exposition (EVS-23), December 2007.

[10] G.-H. Kim and A. Pesaran. "Analysis of Heat Dissipation in Li-Ion Cells \& Modules for Modeling of Thermal Runaway." The 3rd International Symposium on Large Lithium Ion Battery Technology and Application (LLIBTA), Long Beach, California, May 2007.

\section{AUTHORS}

Gi-Heon Kim has worked with the Advanced Vehicles Group at NREL since 2004. His recent research interests in advanced vehicle energy storage system tasks

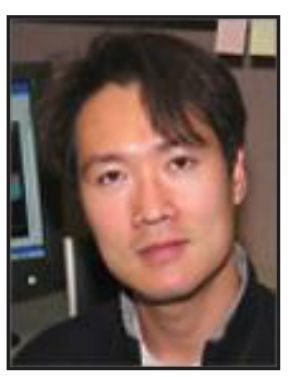

include various model developments for lithium-ion battery thermal abuse model at cell and module levels, 3D electrochemical cell model, electrochemistry-based dynamic battery model, and thermal management system model. He also works on various vehicle power system research topics, such as PEM fuel cell freeze start and alternative fuel-based diesel after-treatment systems. Gi-Heon has a Ph.D. in Mechanical Engineering from Colorado State University and an M.S. and B.S. in Mechanical Engineering from Seoul National University in Seoul, Korea. Phone: 303-275-4437, gi_heon_ kim@nrel.gov.

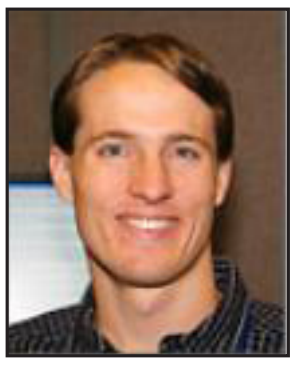

Jeffrey Gonder joined NREL's Center for Transportation Technologies and Systems in 2005. His areas of research include investigating designs and control strategies for hybrid, plug-in hybrid, and fuel cell vehicles. He is also involved in testing and analysis of energy storage devices for advanced vehicles. Before coming to NREL, Jeff developed fuel cell systems and helped lead the design and construction of a plug-in hybrid fuel cell vehicle at Anuvu Inc. in Sacramento, California. Jeff holds a B.S. in Mechanical Engineering from the University of Colorado and an M.S. in Mechanical Engineering from Penn State University, where he also participated in hybrid electric vehicle competitions. Phone: 303-275-4462, jeff_gonder@nrel.gov.

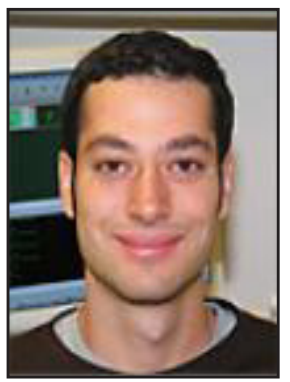

Jason Lustbader has worked in NREL's Center for Transportation Technologies and Systems since 2001. His recent research includes experimental and analytical investigations of energy storage devices for both light and heavyduty HEV and PHEV vehicles. This includes both batteries and double-layer electrochemical capacitors. He is also working on the evaluation and design of thermal management systems for these energy storage devices. His past research includes automotive air-conditioning efficiency and waste heat utilization using thermoelectric devices. Jason holds a B.S. and M.S. in Mechanical Engineering from the University of Colorado, Boulder. Phone: 303275-4443, jason_lustbader@nrel.gov. 


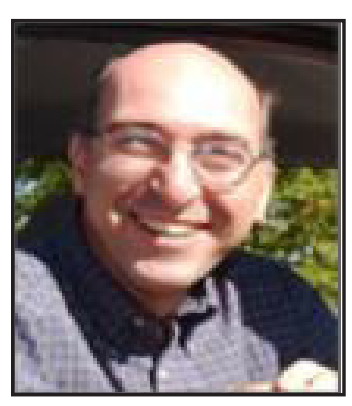

Ahmad Pesaran joined NREL in 1983 and has worked on research in various energy systems, such as solar cooling, ocean thermal energy conversion, air conditioning, desiccant dehumidification for buildings and buses, and, since 1995, HEVs. He is currently the project manager for various activities related to battery thermal characterization, battery thermal analysis, and battery modeling and management. Dr. Pesaran holds a B.S. in chemical engineering from Shiraz University and an M.S. in engineering and a $\mathrm{Ph} . \mathrm{D}$. in mechanical engineering from UCLA. He is a member of the FreedomCAR Electrochemical Energy Storage Technical Team. Phone: 303-275-4441, ahmad_ pesaran@nrel.gov. 